\title{
ELECTRONIC ABSORPTION SPECTRA OF PROTONATED ANTHRACENES AND PHENANTHRENES, AND THEIR NEUTRALS IN NEON MATRICES
}

\author{
Iryna Garkusha ${ }^{1}$, Jan Fulara ${ }^{1,2}$, Adam Nagy ${ }^{1}$, And John P. Maier ${ }^{1}$ \\ ${ }^{1}$ Department of Chemistry, University of Basel, Klingelbergstrasse 80, CH-4056 Basel, Switzerland; j.p.maier@ unibas.ch \\ Received 2010 November 4; accepted 2010 December 14; published 2011 January 31
}

\begin{abstract}
Electronic spectra of three isomers of protonated anthracene and five isomers of protonated phenanthrene have been detected in $6 \mathrm{~K}$ neon matrices following deposition of mass-selected $\mathrm{m} / z=179$ cations produced from dihydro-anthracene or -phenanthrene. The cations exhibit moderately intense band systems in the 400-550 nm range. Corresponding neutrals have been observed in the UV. The absorptions are assigned to specific isomers of the protonated species on the basis of time-dependent density functional theory calculations. The astrophysical relevance of protonated anthracenes and phenanthrenes as candidates for carriers of diffuse interstellar bands is discussed.
\end{abstract}

Key words: ISM: molecules - molecular data - techniques: spectroscopic

Online-only material: color figures

\section{INTRODUCTION}

It has been suggested that protonated polycyclic aromatic hydrocarbons $\left(\mathrm{H}_{-} \mathrm{PAH}^{+} \mathrm{s}\right)$ are important constituents of the interstellar medium (ISM). They may play a catalytic role for the synthesis of $\mathrm{H}_{2}$ (Bauschlicher 1998; Hirama et al. 2004), which likely proceeds in the following steps. The first is formation of $\mathrm{H}-\mathrm{PAH}^{+}$in a reaction of $\mathrm{PAH}^{+}$with $\mathrm{H}$, followed by attachment of a second $\mathrm{H}$ atom to produce $\mathrm{H}_{2}-\mathrm{PAH}^{+}$. The latter dissociates leading to $\mathrm{H}_{2}$, and $\mathrm{PAH}^{+}$is recovered. Protonated PAHs can also be formed in the reaction of atomic hydrogen with $\mathrm{PAH}^{+}$cations, hydrogen-deficient aromatic cations with molecular hydrogen, and that of neutral PAHs with $\mathrm{H}_{3}{ }^{+}$(Le Page et al. 1997; Snow et al. 1998; Herbst \& Le Page 1999). They might be involved in the unidentified infrared (UIR) emission bands (Hudgins et al. $2001)$ at $6.2 \mu \mathrm{m}, \mathrm{C}-\mathrm{H}$ modes of a $\mathrm{CH}_{2}$ group and observed as a shoulder near the strong $3.3 \mu \mathrm{m}$ IR emission band. This has recently stimulated a few gas-phase IR studies on $\mathrm{H}-\mathrm{PAH}^{+} \mathrm{s}$ using mass-selected photodissociation (PD) spectroscopy and the messenger atom method (Ricks et al. 2009), or IR laser multiphoton PD spectroscopy (Knorke et al. 2009). IR spectra of a number of $\mathrm{H}-\mathrm{PAH}^{+} \mathrm{s}$ have been obtained; the spectrum of protonated coronene (Knorke et al. 2009) resembles to some extent UIRs.

Experimental data on the electronic spectroscopy of this class of molecules are scarce. $\mathrm{H}_{-} \mathrm{PAH}^{+} \mathrm{s}$ are known intermediates in organic chemistry and were subject to spectroscopic studies several decades ago. The arenium ions were generated by dissolving PAHs in strong acidic solutions and their properties were investigated by NMR, IR (Olah et al. 1978), and optical methods (Olah et al. 1966; Perkampus \& Baumgarten 1964; Reid 1954). The structure elucidated from these studies is the $\sigma$-complex of the proton attached to the aromatic hydrocarbon moiety. Recent gas-phase studies have reported the electronic spectra of protonated naphthalene (Alata et al. 2010b) and some larger protonated linear acenes (Alata et al. 2010a). They consist of a sharp origin band followed by a complex, unclear pattern.

\footnotetext{
2 Permanent address: Institute of Physics, Polish Academy of Sciences, Al. Lotników 32/46, PL-02668 Warsaw, Poland.
}

The suggestion that protonated PAHs could be responsible for certain diffuse interstellar bands (DIBs) has been put forward (Pathak \& Sarre 2008), because time-dependent (TD) density functional theory (DFT) calculations reveal that some such cations could have strong transitions in the visible domain, where DIBs are detected. To test this, laboratory gas-phase spectroscopic measurements on protonated PAHs are necessary. As a step toward this and to decide which protonated PAHs should be focused on, we have succeeded in measuring the electronic absorption spectra of protonated anthracene and phenanthrene isomers isolated in $6 \mathrm{~K}$ neon matrices using massselected ions. These data are more useful than just the theoretical DFT values as they show unambiguously the wavelength region of the electronic transition and give an indication of their oscillator strength.

\section{EXPERIMENTAL}

The apparatus used in this study was described by Fulara et al. (2010). Protonated phenanthrene and anthracene cations were produced in a hot cathode discharge source from 9,10-dihydro-phenanthrene (9,10DHPh) and 9,10dihydro-anthracene $(9,10 \mathrm{DHAn})$ vapors seeded in helium. The cations were extracted from the source by electrostatic lenses and guided to a quadrupole bender, where they were separated from neutral molecules. The ion beam was then directed into a quadrupole mass filter which was set to transmit only $\mathrm{m} / z=$ $179 \pm 0.5$ cations. These were codeposited with neon onto a rhodium-coated sapphire substrate held at $6 \mathrm{~K}$. The current of the cations arriving at the surface was measured during matrix growth (4-5 hr): total charge was $50-65 \mu \mathrm{C}$ in the case of protonated phenanthrene and $80-85 \mu \mathrm{C}$ for protonated anthracene.

The detection system is a single-beam spectrometer. It consists of a light source (xenon or halogen lamp) and a spectrograph equipped with an open-electrode CCD detector. Broadband light is focused onto the entrance slit of the matrix and propagates $\sim 20 \mathrm{~mm}$ parallel to the substrate surface through the $\sim 150 \mu \mathrm{m}$ neon layer. The beam coming out of the exit slit is focused onto a bundle of 50 quartz fibers, illuminates the diffraction grating of the $0.3 \mathrm{~m}$ spectrograph and is detected by a CCD. The absorption spectra are recorded in several sections covering the $220-1100 \mathrm{~nm}$ range. 


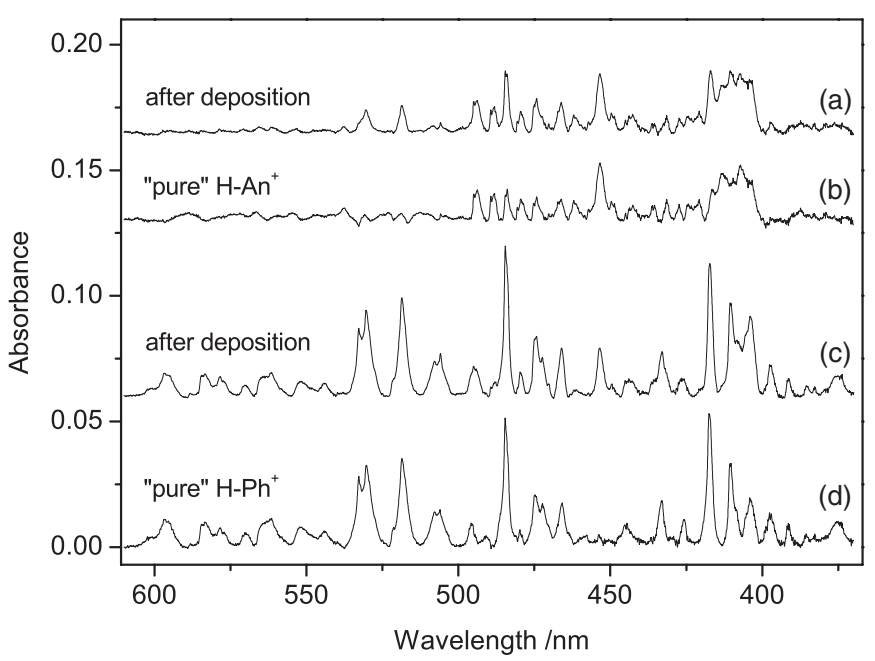

Figure 1. Absorption spectra recorded in a $6 \mathrm{~K}$ neon matrix after deposition of $m / z=179$ cations produced from (a) 9,10-dihydro-anthracene and (c) 9,10dihydro-phenanthrene; (b) spectrum of protonated anthracenes obtained after scaling trace (c) to the same intensity of the distinct absorption at $532 \mathrm{~nm}$ and subtracting it from trace (a); (d) spectrum of protonated phenanthrenes obtained after scaling trace (a) to the same intensity of the absorption at $453 \mathrm{~nm}$ and subtracting it from trace (c).

Due to the high intensity of the broadband light source, care was taken to minimize photoconversion of the species during the recordings. Measurements were always started at the longest wavelength and continued into the UV. Appropriate long-pass filters were also used. In order to check whether photoconversion of the isolated species had taken place during the scans, the spectra were recorded anew.

Ions can be trapped in the matrix efficiently if their electrical charge is balanced with counterions. For this purpose chloromethane was added to the neon in the ratio 1:40,000. Some cations hit metal surfaces of the vacuum chamber and release free electrons. These are attracted by the positively charged matrix and captured by $\mathrm{CH}_{3} \mathrm{Cl}$, which dissociatively forms $\mathrm{Cl}^{-}$ and $\mathrm{CH}_{3}$. The former compensates the charge of the deposited cations. Due to a very low concentration of $\mathrm{CH}_{3} \mathrm{Cl}$ (and even lower of $\mathrm{CH}_{3}$ and $\mathrm{Cl}^{-}$) these species do not perturb the electronic spectra of the trapped cations.

\section{RESULTS AND DISCUSSION}

\subsection{Protonated Anthracene $\left(H-A n^{+}\right)$}

Deposition of $m / z=179$ cations produced from 9,10DHAn into a neon matrix resulted in a number of moderately strong absorption systems in the visible range (Figure 1, trace (a)). Known absorptions of the anthracene cation $\left(\mathrm{An}^{+}\right)$in the near infrared and UV (Szczepanski et al. 1993), and weak ones of the phenanthrene cation $\left(\mathrm{Ph}^{+}\right)$in the near IR (Brechignac \& Pino 1999; Salama et al. 1994) are also present in the spectrum. The reason why bands of $\mathrm{An}^{+}$appear when $\mathrm{H}-\mathrm{An}^{+}$cations are deposited could be the contamination of the precursor sample (9,10DHAn) with An or decomposition of the precursor in the ion source. Of 100 anthracene molecules about 15 contain one ${ }^{13} \mathrm{C}$ atom. Parent ions of the latter isotopologues have the same $m / z$ as $\mathrm{H}-\mathrm{An}^{+}$ions. Fragmentation of $\mathrm{H}-\mathrm{An}^{+}$during growth of the matrix could be another reason for the presence of $\mathrm{An}^{+}$. Weak bands of $\mathrm{Ph}^{+}$in the near IR are likely caused by the contamination of $9,10 \mathrm{DHAn}$ with $9,10 \mathrm{DHPh}$, though isomerization of $\mathrm{H}-\mathrm{An}^{+}$in the ion source resulting in $\mathrm{H}-\mathrm{Ph}^{+}$ cannot be ruled out.

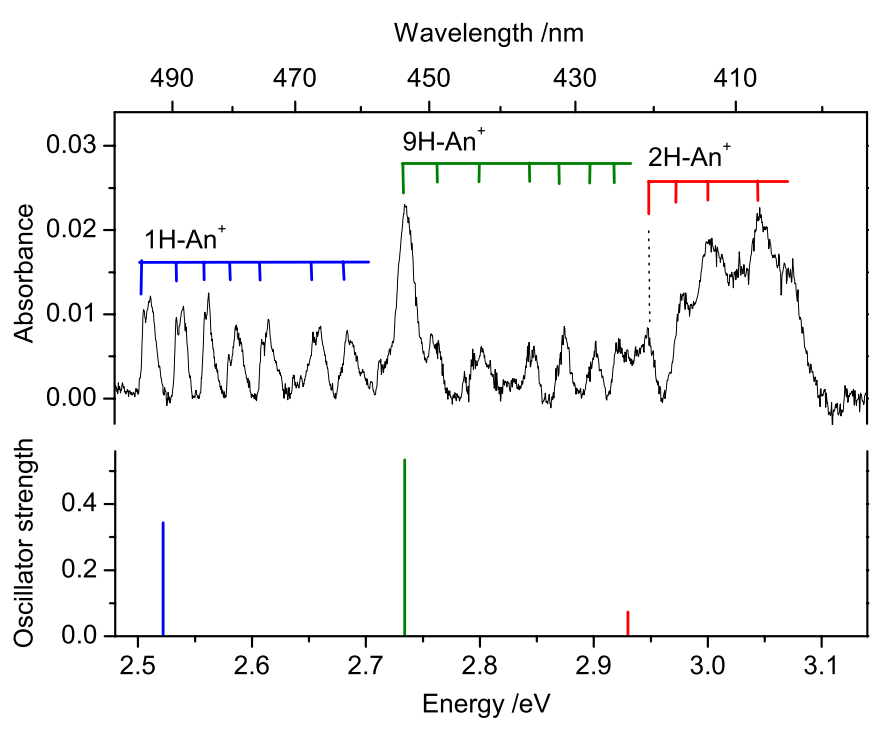

Figure 2. Electronic absorption spectrum of protonated anthracenes compared to the strongest computed excitation energies of the three isomers (stick diagram). Transition energies, calculated with TD DFT at the B3LYP/6-311G $(d, p)$ level of theory, are shifted by $-0.65 \mathrm{eV}$.

(A color version of this figure is available in the online journal.)

In order to test whether the new absorptions seen in Figure 1 (trace (a)) are unique for $\mathrm{HAn}^{+}$, mass-selected $\mathrm{H}-\mathrm{Ph}^{+}$generated from $9,10 \mathrm{DHPh}$ were deposited; the obtained spectrum is shown in trace (c). Comparison of the two spectra reveals some similarity. The strongest bands of $\mathrm{H}_{-} \mathrm{Ph}^{+}$are also seen, although weakly, in the spectrum of $\mathrm{H}-\mathrm{An}^{+}$, indicating that in the $\mathrm{H}-\mathrm{An}^{+}$ experiment $\mathrm{H}-\mathrm{Ph}^{+}$cations were also formed.

To separate absorptions of $\mathrm{H}-\mathrm{Ph}^{+}$from those of $\mathrm{H}-\mathrm{An}^{+}$, the spectrum of the former was subtracted from that of the latter after scaling by an appropriate factor so that the distinct, intense bands of $\mathrm{H}_{-} \mathrm{Ph}^{+}$would have the same intensity in both spectra. The result is trace (b). Comparison of traces (a)-(c) indicates that the electronic spectrum of $\mathrm{H}-\mathrm{Ph}^{+}$also contains the absorptions of $\mathrm{H}-\mathrm{An}^{+}$. They can again be removed by subtraction, after scaling the $\mathrm{H}-\mathrm{An}^{+}$trace by a factor such that the distinct band at $453 \mathrm{~nm}$ has the same intensity in both spectra. The absorption of $\mathrm{H}-\mathrm{Ph}^{+}$is the bottom trace of Figure 1.

The "pure" spectrum of $\mathrm{H}-\mathrm{An}^{+}$is redrawn in Figure 2. The intensities of the bands decrease after UV irradiation of the matrix, confirming its ionic origin. Three band systems are distinguished. The first one with onset at $493.8 \mathrm{~nm}$ shows a long progression built on the $\sim 200 \mathrm{~cm}^{-1}$ mode. Each band of this system has a sharp long-wavelength shoulder, which is spaced from the maximum of the band by $\sim 50 \mathrm{~cm}^{-1}$. It is the zero phonon line, often observed in spectra of matrixisolated species. The strongest band at $453.5 \mathrm{~nm}$ forms the second system; the third system is a group of broad absorptions around $410 \mathrm{~nm}$. The base line was not corrected in this region and may contain a broad bump underneath the absorptions, which could be artificial, due to light interference upon probing the matrix. Wavelengths of the band maxima are collected in Table 1.

Several decades ago $\mathrm{H}-\mathrm{An}^{+}$was studied in strong acidic solutions (Aalbersberg et al. 1959; Dallinga et al. 1958; Gold \& Tye 1952; Reid 1954) and melted salts (Brigodiot \& Lebas 1976; Zingg et al. 1984), and its electronic spectrum was reported. The anthracenium ion $\mathrm{H}-\mathrm{An}^{+}$exhibits a strong, broad absorption with maximum around $410-430 \mathrm{~nm}$ in these environments. Because these spectra were measured in strongly perturbing 
Table 1

Observed Band Maxima and Their Assignments of Protonated Anthracenes and Phenanthrenes, and Their Neutrals in a Neon Matrix

\begin{tabular}{|c|c|c|c|}
\hline$\lambda(\mathrm{nm})$ & $\tilde{v}\left(\mathrm{~cm}^{-1}\right)$ & $\Delta \tilde{\nu}\left(\mathrm{cm}^{-1}\right)$ & Assignment \\
\hline \multicolumn{4}{|c|}{ Protonated anthracenes } \\
\hline 493.8 & 20251 & 0 & $0_{0}^{0}(2)^{1} \mathrm{~A}^{\prime} \leftarrow \tilde{X}^{1} \mathrm{~A}^{\prime} 1 \mathrm{H}-\mathrm{An}^{+}$ \\
\hline 488.2 & 20483 & 232 & $v_{46}$ \\
\hline 484.0 & 20661 & 410 & $2 v_{46}$ \\
\hline 479.4 & 20859 & 608 & $3 v_{46}$ \\
\hline 474.2 & 21088 & 837 & $v_{38}$ \\
\hline 466.1 & 21455 & 1204 & $v_{28-31}$ \\
\hline 462.0 & 21645 & 1394 & $v_{20-23}$ \\
\hline 449.8 & 22232 & 1981 & $v_{38}+v_{28-31}$ \\
\hline 442.7 & 22589 & 2338 & $2 v_{28-31}$ \\
\hline 453.5 & 22051 & 0 & $0_{0}^{0}(2)^{1} \mathrm{~B}_{2} \leftarrow \tilde{X}{ }^{1} \mathrm{~A}_{1} 9 \mathrm{H}-\mathrm{An}^{+}$ \\
\hline 442.7 & 22589 & 538 & $v_{20}$ \\
\hline 435.4 & 22967 & 917 & $v_{17}$ \\
\hline 431.4 & 23180 & 1130 & $v_{15}$ \\
\hline 427.4 & 23397 & 1347 & $v_{11}$ \\
\hline 424.5 & 23557 & 1506 & $v_{20}+v_{17}$ \\
\hline 420.8 & 23764 & 0 & $0_{0}^{0}(2)^{1} \mathrm{~A}^{\prime} \leftarrow \tilde{X}^{1} \mathrm{~A}^{\prime} 2 \mathrm{H}-\mathrm{An}^{+}$ \\
\hline 416.5 & 24010 & 246 & $v_{43}$ \\
\hline 413.3 & 24195 & 431 & $v_{41}$ or $v_{42}$ \\
\hline 407.2 & 24558 & 794 & $v_{35}$ \\
\hline \multicolumn{4}{|c|}{ Hydro-anthracenyl radical } \\
\hline 326.4 & 30637 & 0 & $0_{0}^{0} \mathrm{H}-\mathrm{An}$ \\
\hline 320.7 & 31182 & 545 & \\
\hline 313.2 & 31928 & 1291 & \\
\hline 305.7 & 32712 & 2075 & \\
\hline \multicolumn{4}{|c|}{ Protonated phenanthrenes } \\
\hline 596.6 & 16762 & 0 & $0_{0}^{0}(1)^{1} \mathrm{~A}^{\prime} \leftarrow \tilde{X}^{1} \mathrm{~A}^{\prime} 9 \mathrm{H}-\mathrm{Ph}^{+}$ \\
\hline 578.2 & 17295 & 533 & $v_{42}$ \\
\hline 561.4 & 17813 & 1051 & $2 v_{42}$ \\
\hline 543.7 & 18392 & 1631 & $v_{12}$ \\
\hline 530.3 & 18857 & 0 & $0_{0}^{0}(2)^{1} \mathrm{~A}^{\prime} \leftarrow \tilde{X}^{1} \mathrm{~A}^{\prime} 9 \mathrm{H}-\mathrm{Ph}^{+}$ \\
\hline 518.6 & 19283 & 425 & $v_{44}$ \\
\hline 506.1 & 19759 & 902 & $v_{36}$ or $v_{37}$ \\
\hline 495.5 & 20182 & 1324 & $v_{22-24}$ \\
\hline 465.9 & 21464 & 2607 & $2 v_{22-24}$ \\
\hline 583.3 & 17144 & 0 & $0_{0}^{0}(1)^{1} \mathrm{~A}^{\prime} \leftarrow \tilde{X}^{1} \mathrm{~A}^{\prime} 2 \mathrm{H}-\mathrm{Ph}^{+}$ \\
\hline 570.1 & 17541 & 397 & $v_{45}$ \\
\hline 564.7 & 17709 & 565 & $v_{41}$ \\
\hline 417.4 & 23958 & 0 & $0_{0}^{0}(2) \mathrm{A}^{\prime} \leftarrow \tilde{X}^{1} \mathrm{~A}^{\prime} 2 \mathrm{H}-\mathrm{Ph}^{+}$ \\
\hline 410.5 & 24361 & 403 & $v_{44}$ \\
\hline 404.0 & 24752 & 795 & $2 v_{44}$ \\
\hline 397.4 & 25164 & 1206 & $3 v_{44}$ \\
\hline 391.3 & 25556 & 1598 & $4 v_{44}$ \\
\hline 385.5 & 25940 & 1983 & $5 v_{44}$ \\
\hline 532.8 & 18769 & 0 & $0_{0}^{0}(1)^{1} \mathrm{~A}^{\prime} \leftarrow \tilde{X}^{1} \mathrm{~A}^{\prime} 1 \mathrm{H}-\mathrm{Ph}^{+}$ \\
\hline 518.6 & 19283 & 514 & $v_{42}$ \\
\hline 507.9 & 19689 & 920 & $v_{36}$ \\
\hline 484.5 & 20640 & 0 & $0_{0}^{0}(2)^{1} \mathrm{~A}^{\prime} \leftarrow \tilde{X}^{1} \mathrm{~A}^{\prime} 3 \mathrm{H}-\mathrm{Ph}^{+}$ \\
\hline 474.6 & 21070 & 431 & $v_{44}$ \\
\hline 472.3 & 21173 & 533 & $v_{42}$ \\
\hline 465.9 & 21464 & 824 & $2 v_{44}$ \\
\hline 433.1 & 23089 & 0 & $0_{0}^{0}(2)^{1} \mathrm{~A}^{\prime} \leftarrow \tilde{X}^{1} \mathrm{~A}^{\prime} 4 \mathrm{H}-\mathrm{Ph}^{+}$ \\
\hline 425.8 & 23485 & 396 & $v_{45}$ \\
\hline 551.8 & 18123 & Not assigned & \\
\hline 444.7 & 22487 & Not assigned & \\
\hline \multicolumn{4}{|c|}{ Hydro-phenanthrenyl radical } \\
\hline 375.1 & 26660 & 0 & $0_{0}^{0} 9 \mathrm{H}-\mathrm{Ph}$ \\
\hline
\end{tabular}



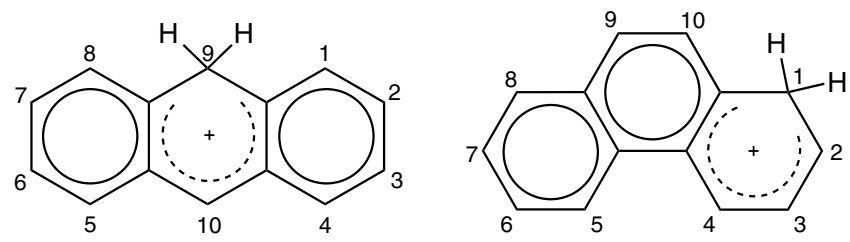

$9 \mathrm{H}-\mathrm{An}^{+}$

$1 \mathrm{H}-\mathrm{Ph}^{+}$

Figure 3. Lowest energy isomers of protonated anthracene and phenanthrene.

media, it is meaningless to compare them with the present neon matrix data.

In order to assign the observed band systems of $\mathrm{H}-\mathrm{An}^{+}, \mathrm{DFT}$ calculations using the B3LYP functional and the 6-311G $(d, p)$ basis set were carried out for three isomers of $\mathrm{H}-\mathrm{An}^{+}$differing in the proton position on the anthracene skeleton. All computations were done using the GAUSSIAN 03 program suite (Frisch et al. 2004). The lowest energy was found for the isomer which has the proton attached at position 9 of anthracene $\left(9 \mathrm{H}-\mathrm{An}^{+}\right)$ (Figure 3). Two other isomers, $1 \mathrm{H}-\mathrm{An}^{+}$and $2 \mathrm{H}-\mathrm{An}^{+}$, lie 36.4 and $49.3 \mathrm{~kJ} \mathrm{~mol}^{-1}$ higher. The values are corrected for zeropoint vibrational energies. Excitation energies of these three isomers of $\mathrm{H}-\mathrm{An}^{+}$were calculated using the TD DFT method at the B3LYP/6-311G $(d, p)$ level of theory and are collected in Table 2. The strongest transition for all considered isomers of $\mathrm{H}-\mathrm{An}^{+}$was predicted in the UV and its excitation energy lies within the 3.2-3.6 eV range. Usually, TD DFT overestimates the excitation energy; this can be by as much as $0.5 \mathrm{eV}$. Taking this into account, the excitation energies of the three isomers are close enough to the onsets of three band systems of $\mathrm{H}-\mathrm{An}^{+}$. The match is even better if a shift of $0.65 \mathrm{eV}$ is used. Corrected electronic transition energies of the three isomers of $\mathrm{H}-\mathrm{An}^{+}$and the corresponding oscillator strengths are displayed in Figure 2.

The onset of the first band system at $493.8 \mathrm{~nm}$ lies close to the calculated transition energy of $1 \mathrm{H}-\mathrm{An}^{+}$. It agrees also well with recent gas-phase photofragmentation data, where the $S_{1} \leftarrow S_{0}$ transition of protonated anthracene was observed at $491.43 \mathrm{~nm}$ (Alata et al. 2010a). The origin of the second system at $453.5 \mathrm{~nm}$ coincides with the calculated excitation energy of $9 \mathrm{H}-\mathrm{An}^{+}$. The broadband system located around $410 \mathrm{~nm}$ has energy close to the predicted transition of isomer $2 \mathrm{H}-\mathrm{An}^{+}$. Therefore, we tentatively assign each band system of $\mathrm{H}-\mathrm{An}^{+}$to its nearestin-energy transition of different isomers. The assignment of individual vibrational bands that form these systems is given in Table 1. It is based on calculated ground-state frequencies of the species considered. In some cases the assignment is not unambiguous, because several modes have frequencies falling within $\pm 30 \mathrm{~cm}^{-1}$ of the observed ones.

Besides the visible absorptions of $\mathrm{H}_{-} \mathrm{An}^{+}$discussed above, the UV range is also relevant for these species. The $295-385 \mathrm{~nm}$ section of the spectrum measured after deposition of $\mathrm{H}-\mathrm{An}^{+}$into a neon matrix is depicted in Figure 4 (trace (b)). The strongest bands are the absorptions of anthracene cation (trace (a)) and neutral anthracene (trace (e)). The reason why $\mathrm{An}^{+}$is present in the matrix when $\mathrm{H}-\mathrm{An}^{+}$was deposited was discussed in the first paragraph of this section. Neutral anthracene appears in the matrix as a result of the neutralization of $\mathrm{An}^{+}$. After stepwise UV irradiation of the matrix new absorptions in the 300-340 nm range appeared and grew in intensity (traces (c) and (d)). They are better seen in the inset of Figure 4 where the bands of $\mathrm{An}^{+}$, which remained after UV irradiation, were removed. The system, which has appeared after UV photobleaching of $\mathrm{H}-\mathrm{An}^{+}$ cations, is of hydro-anthracenyl radical (H-An).

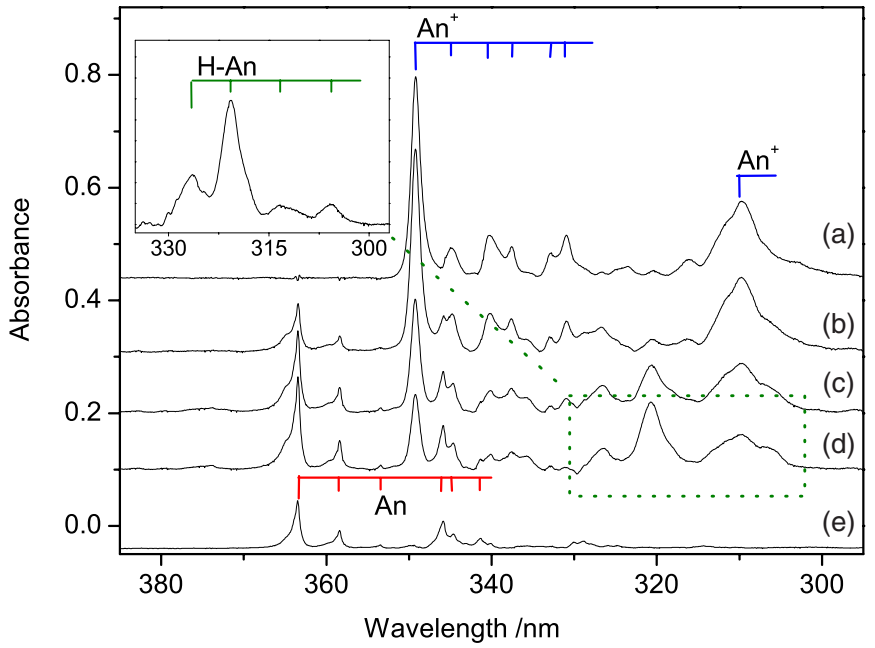

Figure 4. UV part of the absorption spectra recorded after (b) deposition of $\mathrm{C}_{14} \mathrm{H}_{11}{ }^{+}$cations in a $6 \mathrm{~K}$ neon matrix produced from 9,10-dihydro-anthracene, (c) 20 minute and (d) subsequent 25 minute irradiation with a medium-pressure $\mathrm{Hg}$ lamp; (a) and (e) are spectra of anthracene cation $\left(\mathrm{An}^{+}\right)$and neutral anthracene (An), respectively. The inset shows absorption of hydro-anthracenyl radical ( $\mathrm{H}-\mathrm{An})$, appearing as a result of photobleaching of the $\mathrm{H}-\mathrm{An}^{+}$cations. (A color version of this figure is available in the online journal.)

According to TD DFT calculations, two isomers of neutral $\mathrm{H}-\mathrm{An}, 9 \mathrm{H}-\mathrm{An}$ and $1 \mathrm{H}-\mathrm{An}$, have strong transition in the UV range around 342 and $337 \mathrm{~nm}$ respectively (J. Fulara et al. 2010, electronic excitation energies calculated with TD DFT at the B3LYP/6-311G $(d, p)$ level of theory, unpublished). These are close to the observed band system with onset at $326.4 \mathrm{~nm}$. It is difficult to find out from the present experimental data which $\mathrm{H}-\mathrm{An}$ isomer is responsible for the absorptions in this region. It is also possible that both $9 \mathrm{H}-\mathrm{An}$ and $1 \mathrm{H}-\mathrm{An}$ contribute to the spectrum in Figure 4, as the bands have a peculiar intensity distribution and may belong to two overlapping systems.

\subsection{Protonated Phenanthrene $\left(H-P h^{+}\right)$}

The electronic absorption spectrum obtained after massselective deposition of $\mathrm{m} / z=179$ cations produced from 9,10DHPh is presented in Figure 1 (trace (c)), and after removing the absorptions of $\mathrm{H}-\mathrm{An}^{+}$in trace (d). The spectrum is rich in absorption bands, which probably belong to several electronic systems. Thus, a number of UV irradiation experiments were carried out on a matrix containing $\mathrm{H}-\mathrm{Ph}^{+}$ions. These differed in exposure time and wavelength domain of the UV radiation. Spectra recorded after deposition and some irradiation steps are compared in Figure 5. The absorption measured after deposition of the cations is trace (a) and those detected after subsequent UV irradiation are traces (b)-(e). To indicate the changes in intensity of the bands, two spectra measured after different irradiation schemes were subtracted from each other after normalizing them to the same intensity of the specific band (traces (f) and (g)).

The spectra in Figure 5 reveal several electronic band systems, which behave differently under irradiation conditions; this indicates their different origin. Eight band systems of $\mathrm{H}-\mathrm{Ph}^{+}$ could be distinguished after deposition in a neon matrix. The spectrum is redrawn in Figure 6 and the absorptions belonging to the same isomer of $\mathrm{H}-\mathrm{Ph}^{+}$are marked with a specific color.

Seven of the eight systems decrease in intensity after prolonged irradiation with a medium-pressure $\mathrm{Hg}$ lamp (Figure 5, trace (e)). Only the absorption at $375 \mathrm{~nm}$ behaves in an opposite 
Table 2

Excited State Symmetries, Calculated Excitation Energies and Oscillator Strengths for Protonated Anthracenes and Phenanthrenes ${ }^{\mathrm{a}, \mathrm{b}}$

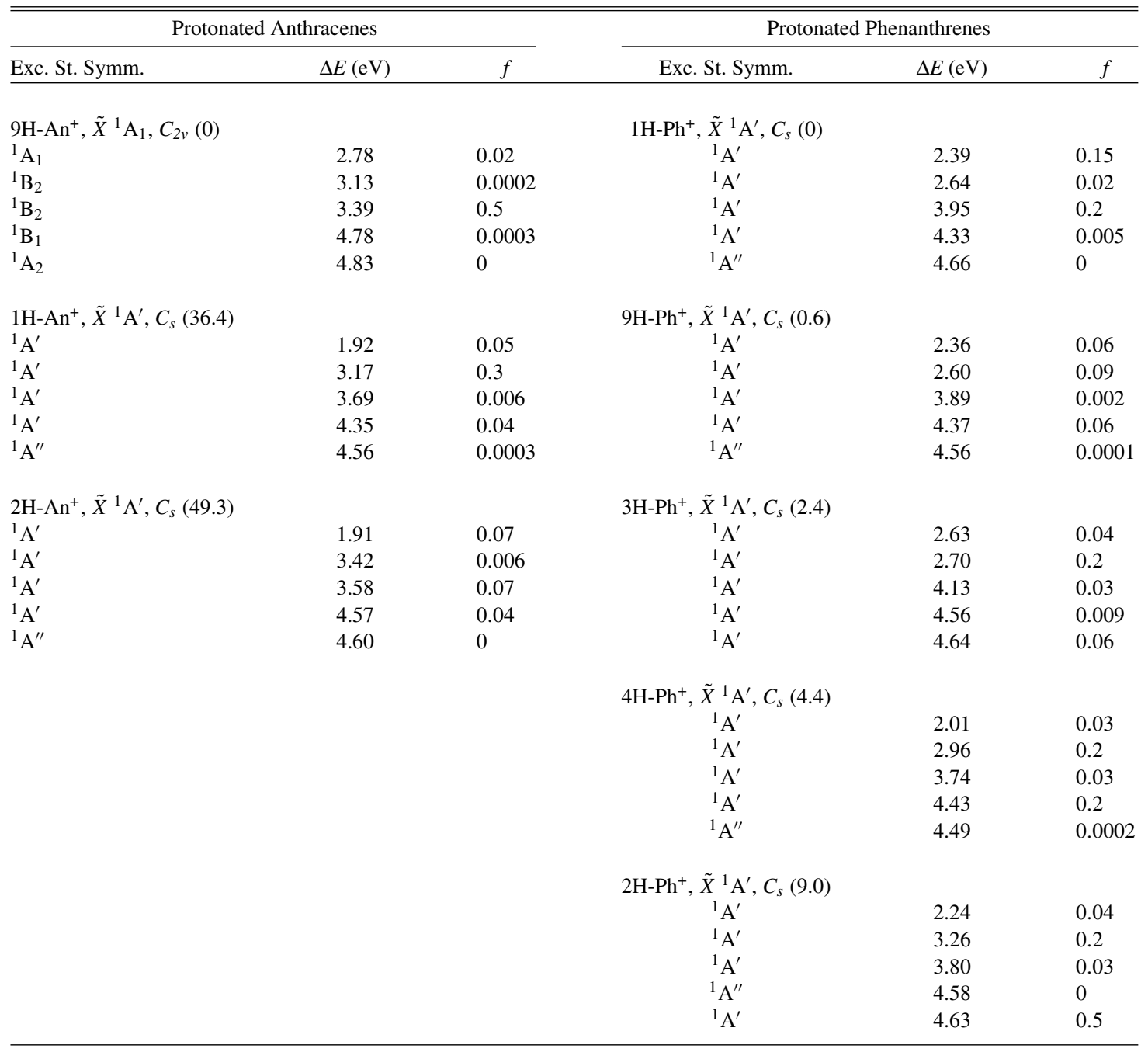

Notes.

a Excitation energies were calculated with TD DFT at the B3LYP/6-311G $(d, p)$ level of theory.

$\mathrm{b}$ Relative ground-state energies $\left(\mathrm{kJ} \mathrm{mol}^{-1}\right)$ with respect to the most stable isomer are given in parentheses.

way. Therefore, it belongs to neutral species. Most likely it is the hydro-phenanthrenyl radical (H-Ph) which should appear in the matrix as a result of the neutralization of $\mathrm{H}-\mathrm{Ph}^{+}$cations. The most stable neutral fragment (phenanthrene molecule), which could be formed from the $\mathrm{H}-\mathrm{Ph}^{+}$ions, can be excluded as a carrier of this band, because it absorbs at shorter wavelengths (Salama et al. 1994) and its systems were also detected in this experiment.

In the past, 9-hydro-phenanthrenyl radical (9H-Ph) was studied in organic solutions. It was produced by hydrogen subtraction from 9,10DHPh (Koizumi et al. 1997) or by hydrogen addition to phenanthrene (Grodkowski et al. 2003; Kawakubo 1980) following pulse radiolysis. The spectrum consists of a broad band with maximum at $395 \mathrm{~nm}$. This is not too far from the observed absorption at $375 \mathrm{~nm}$ for the neutral product in the present experiment. Therefore, the absorption is assigned to the $9 \mathrm{H}-\mathrm{Ph}$ radical.

The other seven systems have ionic origin, because they decrease upon UV irradiation. They belong to different isomers of $\mathrm{H}-\mathrm{Ph}^{+}$. Protonated phenanthrene has been studied in strong acidic solutions and the spectrum exhibits two broad absorptions with maxima at 410 and $520 \mathrm{~nm}$ (Dallinga et al. 1958; Reid
1954). These electronic systems were tentatively assigned to two isomers: $1 \mathrm{H}-\mathrm{Ph}^{+}$and $9 \mathrm{H}-\mathrm{Ph}^{+}$. The spectrum of $\mathrm{H}-\mathrm{Ph}^{+}$in solution covers the same spectral range as in Figure 6. Interaction of solvent molecules with dissolved ionic species is much stronger than with neutrals. Therefore, detailed comparison of these two spectra is of no relevance, in contrast to the neutral hydrophenanthrenyl radical.

In order to deduce which isomers of $\mathrm{H}-\mathrm{Ph}^{+}$are responsible for the spectrum in Figure 6 the ground-state energy of the isomers $1 \mathrm{H}-, 2 \mathrm{H}-, 3 \mathrm{H}-, 4 \mathrm{H}-$ and $9 \mathrm{H}-\mathrm{Ph}^{+}$have been calculated using the DFT method with the B3LYP functional and the 6-311G $(d, p)$ basis set. All considered isomers have similar energies spanning only $9 \mathrm{~kJ} \mathrm{~mol}^{-1}$ (Table 2). The calculations predict $1 \mathrm{H}-\mathrm{Ph}^{+}$to be the most stable isomer, but $9 \mathrm{H}-\mathrm{Ph}^{+}$lies only $0.6 \mathrm{~kJ} \mathrm{~mol}^{-1}$ higher. The highest in energy was found to be $2 \mathrm{H}-\mathrm{Ph}^{+}$, located $9 \mathrm{~kJ} \mathrm{~mol}^{-1}$ above $1 \mathrm{H}-\mathrm{Ph}^{+}$. Because the energy difference of the five isomers is so small, their relative order may change with higher-level calculations.

To assign the spectrum in Figure 6 to a specific isomer of $\mathrm{H}-\mathrm{Ph}^{+}$, excitation energies are needed. TD DFT calculations were carried out for the five isomers considered above. Computed excitation energies and their oscillator strengths are 


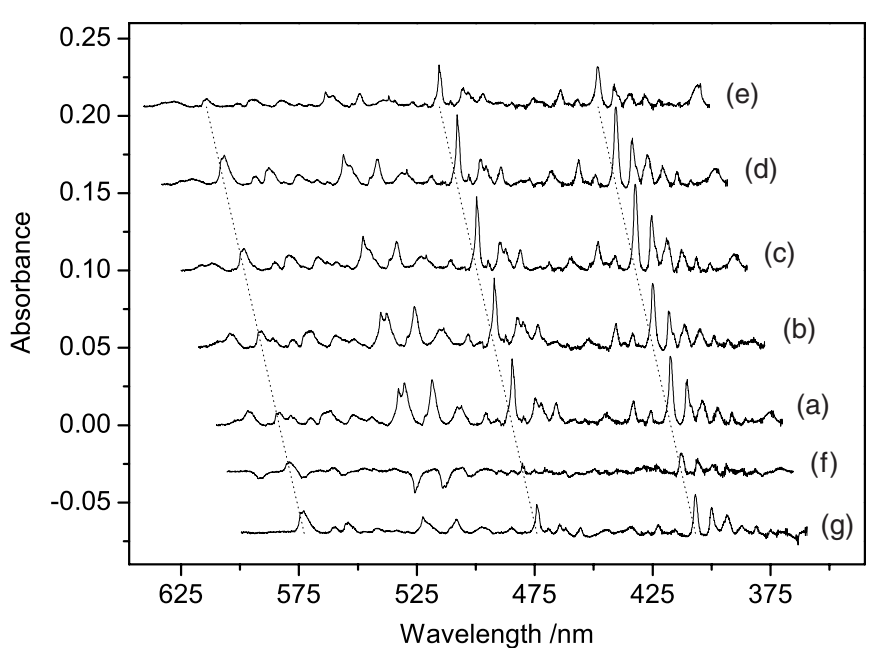

Figure 5. Absorption spectra recorded after deposition of $\mathrm{C}_{14} \mathrm{H}_{11}{ }^{+}$cations in a $6 \mathrm{~K}$ neon matrix produced from 9,10-dihydro-phenanthrene after (a) deposition, (b) exposure to the UV radiation of a high-pressure Xe lamp during measurement, (c) 30 minute and (d) additional 30 minute photobleaching with $390 \mathrm{~nm}>\lambda>250 \mathrm{~nm}$, (e) subsequent 20 minute irradiation with a full mediumpressure $\mathrm{Hg}$ lamp; (f) = (c)-(a) and $(\mathrm{g})=(\mathrm{d})-(\mathrm{e})$ show changes in the intensities of bands following the irradiation steps.

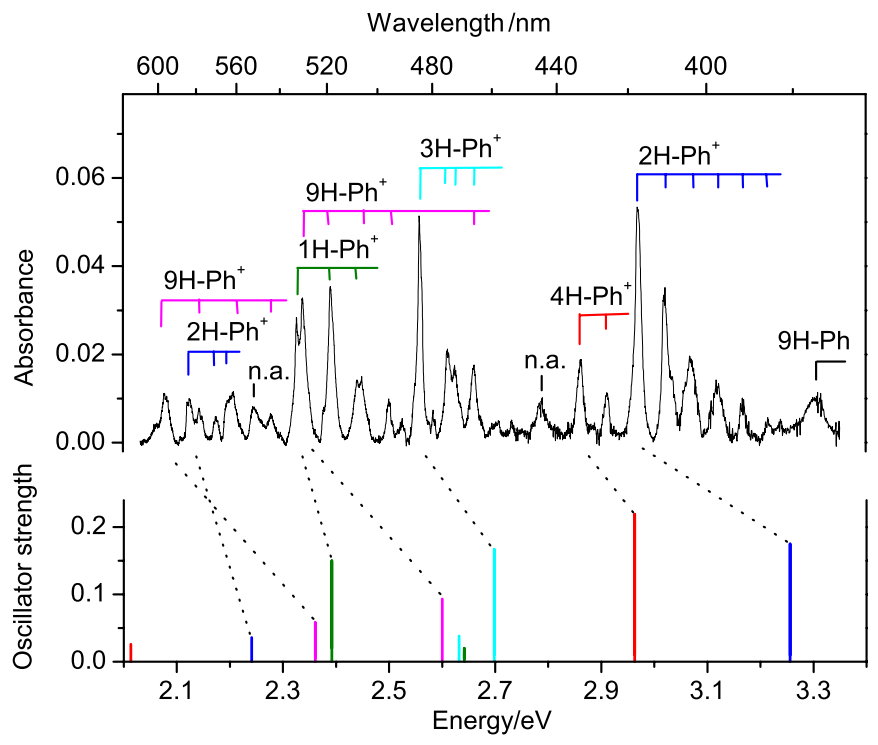

Figure 6. Electronic absorption spectrum of protonated phenanthrenes compared to the excitation energies of the five considered isomers (stick spectrum), calculated with TD DFT at the B3LYP/6-311G $(d, p)$ level of theory; n.a.- not assigned bands.

(A color version of this figure is available in the online journal.)

collected in Table 2 and displayed in Figure 6. All $\mathrm{H}-\mathrm{Ph}^{+}$isomers have two allowed electronic transitions in the visible, where the absorptions of protonated phenanthrenes have been detected. We tentatively assign the observed band systems to specific isomers of $\mathrm{H}-\mathrm{Ph}^{+}$by comparing the excitation energy of its strongest transition with the onset of the nearest system. Dotted lines indicate which isomer is responsible for a certain band system. Individual bands of a given system are assigned using calculated vibrational frequencies of the $\mathrm{H}-\mathrm{Ph}^{+}$isomers in their ground state (Table 1).

\section{RELEVANCE OF $\mathrm{H}-\mathrm{An}^{+}$AND $\mathrm{H}-\mathrm{Ph}^{+}$TO DIBs}

It has been considered that $\mathrm{H}-\mathrm{PAH}^{+} \mathrm{s}$ could be carriers of

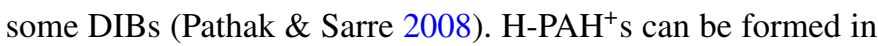
the ISM in ion-molecule reactions of hydrogen-deficient $\mathrm{PAH}^{+}$ cations with $\mathrm{H}_{2}$, of atomic hydrogen with $\mathrm{PAH}^{+}$or neutral PAHs with highly abundant $\mathrm{H}_{3}{ }^{+}$. All the above mechanisms assume the presence of $\mathrm{PAH}^{+}$ions in the ISM; therefore, their astrophysical relevance should also be discussed.

The present spectroscopic studies on protonated anthracene and phenanthrene allow a direct comparison of their transition intensities with the anthracene $\mathrm{An}^{+}$and phenanthrene $\mathrm{Ph}^{+}$ cations. The electronic transitions of $\mathrm{An}^{+}$and $\mathrm{Ph}^{+}$in the near IR are an order of magnitude stronger than the visible absorptions of the protonated species.

The electronic transition of $\mathrm{Ph}^{+}$in a neon matrix (Salama et al. 1994) and in the gas phase, as the $\mathrm{Ph}^{+}-\mathrm{Ar}$ complex (Brechignac $\&$ Pino 1999), have been reported. The position of all bands reported in neon agrees well with our studies; however, their relative intensities in the near IR system are different. In the present mass-selective experiment, besides $\mathrm{Ph}^{+}$the absorption of neutral phenanthrene has also been detected in the UV. The oscillator strength of the near IR band system of $\mathrm{Ph}^{+}$is evaluated to be 0.25 by measuring the change of the intensity of cationic and neutral phenanthrene absorptions induced by UV irradiation of the matrix, and using the experimental oscillator strength of the latter (Clar 1964). This value is about four orders of magnitude higher than that reported by Salama et al. (1994), but is close to the gas-phase value $(0.15 \pm 0.05$; Brechignac \& Pino 1999). High oscillator strength of the near-IR transition of $\mathrm{Ph}^{+}$ is confined mainly to the origin band at $892 \mathrm{~nm}$ and makes it favorable for the search in the ISM. $\mathrm{An}^{+}$, similarly to $\mathrm{Ph}^{+}$, has a strong electronic transition in the near-IR region with the onset around $709 \mathrm{~nm}$, as well as about a five times stronger system around $349 \mathrm{~nm}$ (in a neon matrix). The latter could be used for a sensitive detection of $\mathrm{An}^{+}$.

The results of the present spectroscopic study on protonated anthracene and phenanthrene isolated in neon matrices reveal that their electronic transitions fall in the $400-550 \mathrm{~nm}$ range, where a number of broad DIBs are found (Jenniskens \& Désert 1994; Hobbs et al. 2008). Several isomers of these species are detected in the neon matrix; they have moderately intense absorption systems. In the case of protonated phenathrene, all five isomers have energies within $9 \mathrm{~kJ} \mathrm{~mol}^{-1}$ of each other. If $\mathrm{H}-\mathrm{Ph}^{+}$is formed in the reaction of neutral phenanthrene with $\mathrm{H}_{3}{ }^{+}$in the ISM, then these five isomers should be about equally populated, and hence their column density in a specific line of sight would be lower than for $\mathrm{Ph}^{+}$. This and the lower oscillator strength of the visible transition of protonated phenathrenes in comparison with the near IR one of $\mathrm{Ph}^{+}$could hamper their optical detection in the ISM. Similar arguments apply to the detection of $\mathrm{H}-\mathrm{An}^{+}$. More promising are the protonated PAHs which form fewer isomers (e.g., coronene) and if they have a larger oscillator strength.

This work has been supported by the Swiss National Science Foundation (project no. 200020-124349/1).

\section{REFERENCES}

Aalbersberg, W. I., Hoijtink, G. J., Mackor, E. L., \& Weijland, W. P. 1959, J. Chem. Soc., 3049

Alata, I., Dedonder, C., Broquier, M., Marceca, E., \& Jouvet, C. 2010a, http://hal.inria.fr/inria-00505242/en/

Alata, I., Omidyan, R., Broquier, M., Dedonder, C., Dopfer, O., \& Jouvet, C. 2010b, Phys. Chem. Chem. Phys., 12, 14456

Bauschlicher, C. W. 1998, ApJ, 509, L125

Brechignac, P., \& Pino, T. 1999, A\&A, 343, L49

Brigodiot, M., \& Lebas, J. M. 1976, J. Mol. Struct., 32, 311

Clar, E. 1964, Polycyclic Hydrocarbons Vol. 1 (New York: Academic) 
Dallinga, G., Mackor, E. L., \& Stuart, A. A. V. 1958, Mol. Phys., 1, 123

Frisch, M. J., et al. 2004, Gaussian 03, Revision C.01 (Wallingford, CT: Gaussian, Inc.)

Fulara, J., Nagy, A., Garkusha, I., \& Maier, J. P. 2010, J. Chem. Phys., 133, 024304

Gold, V., \& Tye, F. L. 1952, J. Chem. Soc., 2172

Grodkowski, J., Neta, P., \& Wishart, J. F. 2003, J. Phys. Chem. A, 107, 9794

Herbst, E., \& Le Page, V. 1999, A\&A, 344, 310

Hirama, M., Tokosumi, T., Ishida, T., \& Aihara, J. 2004, Chem. Phys., 305, 307

Hobbs, L. M., et al. 2008, ApJ, 680, 1256

Hudgins, D. M., Bauschlicher, C. W., \& Allamandola, L. J. 2001, Spectrochim. Acta A, 57, 907

Jenniskens, P., \& Désert, F.-X. 1994, A\&AS, 106, 39

Kawakubo, T. 1980, Mol. Cryst. Liq. Cryst., 62, 41

Knorke, H., Langer, J., Oomens, J., \& Dopfer, O. 2009, ApJ, 706, L66

Koizumi, H., Fukamura, S., Ichikawa, T., Yoshida, H., \& Kubo, J. 1997, Radiat. Phys. Chem., 50, 567
Le Page, V., Keheyan, Y., Bierbaum, V. M., \& Snow, T. P. 1997, J. Am. Chem. Soc., 119, 8373

Olah, G. A., Pittman, C. U., Waack, R., \& Doran, M. 1966, J. Am. Chem. Soc., 88,1488

Olah, G. A., Staral, J. S., Asencio, G., Liang, G., Forsyth, D. A., \& Mateescu, G. D. 1978, J. Am. Chem. Soc., 100, 6299

Pathak, A., \& Sarre, P. J. 2008, MNRAS, 391, L10

Perkampus, H.-H., \& Baumgarten, E. 1964, Angew. Chem., Int. Ed. Engl., 3, 776

Reid, C. 1954, J. Am. Chem. Soc., 76, 3264

Ricks, A. M., Douberly, G. E., \& Duncan, M. A. 2009, ApJ, 702, 301

Salama, F., Joblin, C., \& Allamandola, L. J. 1994, J. Chem. Phys., 101, 10252

Snow, T. P., Le Page, V., Keheyan, Y., \& Bierbaum, V. M. 1998, Nature, 391, 259

Szczepanski, J., Vala, M., Talbi, D., Parisel, O., \& Ellinger, Y. 1993, J. Chem. Phys., 98, 4494

Zingg, S. P., Dworkin, A. S., Sorlie, M., Chapman, D. M., Buchanan, A. C., \& Smith, G. P. 1984, J. Electrochem. Soc., 131, 1602 